Portland State University

PDXScholar

$5-2013$

\title{
Online Mental Health Information Seeking in Young Adults with Mental Health Challenges
}

L. Kris Gowen

Portland State University, gowen@pdx.edu

Follow this and additional works at: https://pdxscholar.library.pdx.edu/rri_facpubs

Part of the Social Work Commons

Let us know how access to this document benefits you.

Citation Details

Published as: L. Kris Gowen (2013) Online Mental Health Information Seeking in Young Adults with Mental Health Challenges, Journal of Technology in Human Services, 31:2, 97-111.

This Post-Print is brought to you for free and open access. It has been accepted for inclusion in Regional Research Institute by an authorized administrator of PDXScholar. Please contact us if we can make this document more accessible: pdxscholar@pdx.edu. 
Online mental health information seeking in young adults with mental health challenges

L. Kris Gowen, PhD, EdM

Senior Research Associate,

Regional Research Institute of Human Services,

Portland State University

Contact information:

L. Kris Gowen, PhD, EdM

Regional Research Institute

1600 SW 4th Ave, Suite 900

Portland, OR 97201

Phone: 503-725-9619

Fax: 503-725-4180

Email: gowen@pdx.edu

Keywords: mental health, young adult, internet, information seeking

Funding for this research was provided by the National Institute on Disability and Rehabilitation Research (NIDRR), and the Substance Abuse Health and Services Administration. The author would like to thank Matthew Deschaine for his contributions and the Research and Training Center on Pathways to Positive Futures for its support.

\section{Author Description:}

L. Kris Gowen, PhD, EdM is a Senior Research Associate at the Regional Research Institute of Human Services within Portland State University School of Social Work. Her research interests focus on the development of communities that promote positive youth development with emphases on mental health, sexuality and positive cultural identity. 
Online mental health information seeking in young adults with mental health challenges

\begin{abstract}
Barriers such as stigmatization and access to health care may lead young adults with mental health conditions (YAMHC) to try to find alternatives to more traditional means of obtaining care. One possible alternative is to seek information online. The purpose of this paper is to better understand how YAMHC use the internet to access information about mental health, and the challenges they face when trying to access that information. Semi-structured focus groups were conducted to investigate how YAMHC use the internet for information and support regarding their mental health. Three major themes about mental health information seeking emerged from the data: (1) Topics searched; (2) Motivations for going online to search for information; and, (3) Barriers to successful searching. Findings indicate that YAMHC look up information related to their mental health for a variety of reasons that are unique to the online experience, and use that information to help them with their care, despite at times feeling overwhelmed by, and not always trusting of, the information available.
\end{abstract}




\section{Introduction}

Transition from adolescence to adulthood involves both contextual and social role changes and is marked by increased flexibility and self-direction (Schulenberg, Sameroff, \& Cicchetti, 2004) both which can translate into a higher level of acting and living more independently. For this reason and others, Arnett (2000) states that this developmental period or emerging adulthood should be considered unique in its own right.

Young adults with mental health conditions (YAMHC) face additional complications in their transition to adulthood as they try to manage their mental health. First, their mental health status is often accompanied by stigmatization from themselves and others (Biddle, Donovan, Sharp, \& Gunnell, 2007; Vogel, Wade, \& Haake, 2006). During a time of identity formation and establishment of a close peer group, and possible long-term romantic partner (Arnett, 2000), experiences with stigmatization can delay or prevent altogether the seeking of mental health care and support (Biddle, et al., 2007; Vogel, et al., 2006). Policies associated with becoming an “adult” also impact access to mental health care. Separate child and adult systems have their own rules defining who is eligible for services, and YAMHC often struggle with how to access services when they need to change services after "aging out” of child mental health care (Davis \& Sondheimer, 2005; Davis \& Koroloff, 2006). For example, young people often face more restrictive eligibility requirements at age 18-22, depending on state of residence (Pottick, Bilder, Stoep, Warnder, \& Alvarez, 2008). Additionally, insurance coverage may change as YAMHC no longer qualify as dependents under their parents’ health plans, or are no longer covered under public health insurance; young adults in general are disproportionately uninsured or inadequately 
insured in the United States (Fishman, 2001; Callahan \& Cooper, 2005; Callahan \& Cooper, 2006; Fishman, 2001; McManus, Newacheck, \& Greaney, 1990).

These significant barriers to accessing care do not preclude a young adult's need to receive supports and services for their mental health conditions. However, these barriers may leave young adults trying to find alternatives to more traditional means of obtaining care. One possible alternative is to seek information and support online concerning their mental health condition.

Most young adults aged 18-29 (79\%) look up health information online; 33\% look up information about mental health issues, 38\% look up information on prescription or over the counter drugs, and 34\% look up alternative treatments or medicines (Fox \& Jones, 2009). Adults with mental health conditions are particularly likely to use the internet to access mental health information (Powell, 2006). In a population of adult psychiatric patients in Switzerland, 65\% were internet users (Khazaal, Chatton, Cochand, Hoch, Khankarti, Khan, \& Zullino, 2008); of those, $68.5 \%$ searched for information on their diagnosis (72.7\%), different treatment options (84.6\%) and medication side effects (81.8\%).

What potentially makes the use of online mental health information problematic, is that the quality of this information is not always trustworthy. The overall quality of online information on depression (Griffiths \& Christensen, 2000), social phobia (Khazaal, Fernandez, Cochand, Reboh, \& Zullino, 2008), and substance addictions (e.g., Khazaal, Chatton, Cochland, \& Zullino, 2008) is low. A review of the quality of mental health information on the internet concluded that overall quality is low, but that information on affective disorders may be improving (Reavley \& Jorn, 2011). 
There is some research that implies online health information seekers are wary of the quality of mental health information- but that does not stop them from using the internet to obtain information, or always lead them to evaluate the quality of the information accessed. Among adults with mental health conditions, the internet was ranked $6^{\text {th }}$ in terms of accurate sources of information about mental health, but $3^{\text {rd }}$ among information sources used (Powell, 2006). About $25 \%$ of health information seekers are vigilant about verifying online information, another quarter report taking casual steps to assess the quality of online health information, and half relies on common sense when deciding to trust online health information (Fox \& Rainie, 2002). About half of adult online health information seekers have read someone else's commentary or experience about health or medical issues on an online news group, website, or blog (Fox \& Jones, 2009) - a potentially dubious source for quality health information. The abundance of low-quality mental health information online and the limited skills demonstrated by internet users to search for information skillfully adds to the need for teaching eHealth literacy (Skinner, Maley, \& Norman, 2006).

Adding to the issue of low-quality mental health information online is the challenge of low levels of eHealth literacy among those with serious mental health conditions. When searching online for mental health information, over half of adult psychiatric patients (55.4\%) report that the information sought was either partially found, or not found at all (Khazaal, et al., 2008). A study including at-risk youth found several barriers that prevented them from successfully accessing quality health information online. The young people in this study reporting feeling overwhelmed at the amount of information available yet were not able to find answers to their specific questions, nor did they find information tailored to their needs. Ensuring privacy while accessing sensitive health information online was cited as relevant, but not always possible due to 
accessing the internet in public locations such as school or a library, or having parents monitor their online usage. Finally, online health information was often text-heavy, presenting a barrier to those with low literacy levels (Skinner, Biscope, Poland, \& Goldberg, 2003).

Thus, while there is some research on the quality and use of online mental health information, there is scant research done specifically on the subpopulation of YAMHC, despite their need for such a resource. The purpose of this paper is to begin to develop an understanding how YAMHC use the internet to access information about mental health, and the barriers they face when trying to access that information.

\section{Method}

Given the lack of previous literature on this topic, qualitative research methods were used to produce an in-depth understanding of topics. Three semi-structured focus groups were conducted in Oregon to investigate how young adults with mental health conditions use the internet for information and support regarding their mental health. Focus groups were chosen as the method of data collection because they allow participants to share their experiences with others, which in turn has the potential to trigger thoughts and ideas from others. The use of focus groups has been found to be an effective way in studying under-researched phenomena (Kruger \& Casey, 2008), . Two groups were conducted in two separate urban areas; one of these was held in a location unfamiliar to participants, while the other was held at a clubhouse for youth with mental health challenges. A third focus group was held at a group home. All participants received light refreshments and $\$ 20$ for their participation.

\section{Procedure}


Participant Recruitment. All procedures were approved by the (Name removed) State University Institutional Review Board. Prior to the focus groups, participants were recruited to the neutral location using Craigslist, while participants for the other two focus groups were recruited through program leaders from the hosting sites. Those potential participants who were recruited through Craigslist received an email describing the focus group and directing them to an online survey that determined their eligibility. Although young adults of all genders, races, and ethnicities are welcome to participate in our focus groups, there were three eligibility criteria/restrictions: (1) The age of participants was restricted to those between the ages of 18-30; (2) Participants must report regular internet access, defined as being online at least weekly; and, (3) Participants must have a mental health condition; eligibility was assessed through self-report via an adaptation of the Children with Special Health Care Needs (CSHCN) Screening Tool (Bethell, Read, Stein, Blumberg, Wells, \& Newacheck, 2002), and the K-6 (Kessler, et. al, 2003).

Participants in the other two focus groups, which were based in two mental health organizations (one youth drop-in center, one group home), were recruited via a leader within the organization. The leader gave an informational flyer to those within their organization, and invited those interested to participate. Given that these organizations served persons with mental health challenges within the target age group, no screeners were administered to determine eligibility.

At the start of each focus group, each participant read and signed a consent form prior to participation. The consent form notified participants about the use of audio recording. Before the actual focus group began, a brief questionnaire was given to participants that collected information on demographics and internet use. 
Focus Group Procedures. Ground rules were set at the start of each focus group to remind participants of the voluntary and confidential nature of the project. The focus group protocol was designed to prioritize the experiences of youth, and their ideas for solutions to undesired experiences. First, questions around participant experiences with looking up mental health information were drawn from their everyday experiences (Kamberelis \& Dimitriadis, 2005). Sample questions include: "Where you like to get information about your mental health condition?" and "What web sites have you gone to in order to get information about mental health?” Second, utilizing a “problem solving approach” (Kamberelis \& Dimitriadis, 2005, p. 903), another goal of the focus groups was to hear participants' ideas for how to improve their online searches for mental health information. Sample questions include: "What would make mental health web sites more useful for you?" and "What advice would you have for a young person who has been recently diagnosed with a mental health condition and wants to find out more about his/her condition?”

\section{Data Analysis}

Questionnaire data were analyzed descriptively via SPSS.

Given the lack of previous research on the internet searching habits of young adults with mental health challenges, a qualitative, iterative process of data analysis was utilized in this study in order to allow the data itself to determine the coding themes. Thus, a thematic approach was used to analyze data (Boyatzis, 1998). Using an open axial coding process, themes were derived from the data (Marshall \& Rossman, 2011).

Digital recordings from each focus group were transcribed verbatim, with the exception of the omission of any identifying information. Next, the author and an additional coder conducted an 
initial reading of one focus group transcript, separately creating initial coding schemes from the data. The two coders then met to compare and reconcile their coding scheme, which was finalized and implemented on all three transcripts. This was done by having both coders review each of the three focus groups independently in order to place participant statements into the themes established. After this independent coding process, the coders met to compare codes and resolve any discrepancies. This was done by having the author read through each transcript separately, and identifying quotes that were coded under a particular theme. When there was a discrepancy between the two coders, the item was discussed until consensus was established on a particular code. After the coding was completed, a subgroup of participants from one of the focus groups was brought back to meet and discuss the findings and coding schemes. This group offered their critique of the findings which were incorporated into the final analysis presented here.

\section{Results}

Three focus groups, 27 people, average age 21.3 (SD = 3.8; range18-30). Majority male (63\%, $\mathrm{n}=17), 33 \%$ female $(\mathrm{n}=9)$ and one trans-identified young adult. Vast majority identified

themselves as white ( $\mathrm{n}=20 ; 74 \%)$; 3 identified as Hispanic (11\%), 3 as American Indian/Alaska Native (11\%), and one African American (4\%).

\section{Quantitative Findings on Internet Use}

Regarding internet use, $60 \%$ stated that they use the internet "several times a day;” $62.5 \%$ listed home as the most common place for internet access, followed by the library (12.5\%), work (8.3\%), other family member’s house (8.3\%), community center (4.2\%), and other location $(4.2 \%)$. 
The vast majority of focus group participants (89\%) stated that they have looked up mental health information online. Over half (63\%) reporting looking up mental health information online every few weeks or less frequently; in contrast, 15\% stated they looked up information daily, and an additional 11\% stated that they looked up information weekly.

\section{Qualitative Findings on Mental Health Information Searching}

Three major themes about mental health information seeking emerged from, and were represented in, all three focus groups: (1) Mental health topics searched for online; (2) Motivations for going online to search for mental health information; and, (3) Barriers to successful searching.

Mental Health Topics. Although young adults reported searching for many different types of information online, these searches primarily revolved around five major topics related to their mental health: (1) Medications, (2) Diagnoses, (3) Treatment Options, (4) Access to Health Care, and (5) Supports and Resources.

Medications. Information about medication was the topic most commonly discussed across all three focus groups. Young people report being very interested in gathering more information about the medications they were prescribed. They want to know about the side effects, the symptoms they are supposed to treat, and even the diagnosis associated with the medication. One young woman stated, "when I get a new medication I always look it up [online] because I am really scared of medications. I need to know every side effect that anyone could possibly get.” One participant looked up information online to determine "the side effects and what this drug is going to do for me.” 
Diagnoses. Participants across all three focus groups also mentioned looking up information about diagnoses, such as the prevalence of a mental health condition in the general populations (“how common is this disorder?”), basic symptoms, or causes of a condition: One young man stated: "I find out how I or others could get it, if it is hereditary, if it is purely random, if it has to do with trauma."

Some focus group participants used the internet to self-diagnose themselves - a precursor to seeking formal mental health care: "I remember that when I was young I was already diagnosing myself on the internet because you can look up the things you are experiencing."

Treatment Options. Participants in two of the three focus groups discussed wanting to know more about different treatment options, often, but not always, outside of medication. Such treatment options often included alternative therapies, such as acupuncture and lifestyle changes. One male participant stated: "One of things that I have been looking at is alternative treatments, naturopathic, homeopathic and meditation -- the whole nine yards.”

Access to Healthcare. Participants in two of the three focus groups discussed using the internet to assist them in accessing health care. Information concerning access to healthcare encompassed a wide range of subcategories from using the internet to find a healthcare provider that fit under a particular insurance plan and/or accepted clients on a sliding scale, to looking up transportation routes to a health clinic. One woman from the urban focus group stated that she looked up information on "practitioners and psychologists... who are in my preferred network." Another female participant from a different group stated that she often looked up care options at the “county mental health clinic” website. 


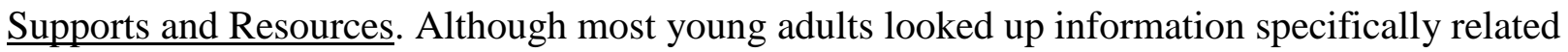
to the treatment of their mental health condition, some focus group participants across all three groups stated they looked up other issues related to their mental health condition that were more related to transitioning to adulthood, which, to them, meant living more independently. Specific topics under this category included both practical supports (e.g., where to go to get food stamps), as well as more emotional supports (e.g., coping skills one can learn on one’s own).

Motivations for going online for mental health information. Just as focus group participants reported many topics searched for online related to their mental health, there were also several reasons for looking up this information. These motivations were coded into five different categories: (1) Seeking Out Additional Information; (2) Seeking Out Community; (3) Nowhere Else to Turn; (4) Preparing for a Mental Health Visit, and; (5) Anonymity.

Seeking Out Additional Information. There were many reasons focus group participants across all three groups gave for wanting access to more information about their mental health. These reasons included looking up terms used by a mental health care provider that they did not understand, using the internet as a starting place to look up information about a diagnosis they knew little about, and wanting to know about the history of their mental health condition:

Generally I like to look up and do research. Like when I heard new labels like 'bipolar’ and 'schizophrenia', I like to do research on how they are similar and how they are different...so I went on a lot of websites to compare different things.

One of the most common motivations for searching out additional information online, however, was to either challenge or confirm something heard elsewhere (usually from a mental health 
provider). One male participant stated: "Even after going to the doctor, when he prescribes me medicine, I will go and look it up [online].” Another female participant echoes this sentiment:

I like that you can look up the prescription that your psychiatrist is writing you. Because sometimes you get a new psychiatrist, or a crazy one, or one that you can’t trust. They are just like 'take this [medication]' - this is what you need. So I look it up online and learn all the side effects and then I can go back to him and say 'why do you think I am psychotic?'

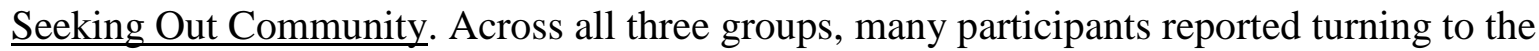
internet to find others "like themselves" who have the same mental health diagnosis and/or take the same medications as they did. Typically, finding such community was accomplished through reading message boards and blogs. Said one transgender young adult:

My favorite mental health site is run by this guy who has done all this research on anti-depressants, anti-psychotic medications... and puts it into words you can understand. And there is a message board you can go to and ask like does Remrod make you want to eat sugar and find that yeah it does.

Some participants sought out online communities in order to read accounts of personal experiences with living with a particular condition or about the "real" side effects of a medication. Some participants, however, simply wanted to feel as though they were not alone, and stated that online "the community is really important." One participant stated that he had "never met anyone who was bipolar before I met them on the internet and they told me their experiences personally." Another stated that it was important for her to know that "those of us with mental health conditions are not alone. I think the internet validates that.” 
Nowhere else to go. In two of the three groups, participants reported turning to the internet because they could not afford to receive more formal mental health care because of a lack of insurance and other financial resources. One young man stated:

When I turned 18 I stopped [getting mental health care] and went to one therapy session because I didn’t have my mom’s insurance anymore. So suddenly it became about what resources I had access to myself, so from the medical field of mental health to the internet field of mental health - that was my transition.

Another stated that time of day matters when trying to access information: "if it is two in the morning and you need some information, it is right there at your finger tips.”

Preparing for a Mental Health Visit. Given the range of information available online, participants in two of the groups reported using the internet to prepare for visits with mental health professionals. Such preparation included looking up doctor’s educational backgrounds and ratings online, to looking up information about their mental health conditions so that they were a more informed client:

[Online] I can learn about the breadth of information [about my mental health] at least so, when I see a doctor and someone tells me what I have I, at least have a basis of foundation for what is going on. So I think that for young people are getting diagnosed these days, I bet that 50 percent or 75 percent of them already have some information about what is going on with themselves.

There are sites you can go to and they rate or write comments about doctors, so you can see if someone, like, gets four out of five stars. 
Anonymity. A few participants in two of the groups explicitly stated that the anonymity of the online environment makes it an appealing place to look up information about mental health. One woman stated: “The internet is private, there is no one there questioning me or what I'm looking up. It’s personal and totally under my control.”

Barriers to Successful Online Information Searching. Despite using the internet to access mental health information, focus group participants also stated that they sometimes encountered barriers to finding desired information. These barriers were coded into two categories (1) Information Overload; and, (2) Concern over Information Accuracy.

Information Overload. Some participants expressed "frustration” and "being overwhelmed” over the amount of information one can acquire online. They spoke of having to sort through thousands of links and “Googling and Googling” until they found the information needed. One young man expresses his frustration when attempting an internet search:

If you have a search engine like Google or something like that you type one thing in say "schizophrenia" to see what the symptoms are, it might show a bunch of things with schizophrenia in the title and it might have a whole paper on what the symptoms of schizophrenia are, and then you click on another link and it might bring up a YouTube video of a dude freaking out. It gets really hard to make it specific, and that's for anything on the internet and it's what frustrates me so much about it when I use the computer.

Concern over Information Accuracy. Many focus group participants recognized that online information is not always accurate; they state that some sites “lie” or “can’t be trusted.” One 
female participant mentioned that pharmaceutical websites are not a good source of information because:

They manipulate you. It is a marketing scheme...If you just take the [online] quiz and it comes up “depression,” it’s like “here is a coupon for this.” They don’t care about what is going on. They just want you to buy their drug.

Other participants mentioned that personal accounts, while appealing on some level, also can be sources of misinformation. For example, one young man stated:“I don’t really trust those things [message boards]...people would say irrelevant things. They contradict. They are putting their two cents in and it's only worth a half cent." Similarly, a young woman warned, "I think a lot of people forget that if you look up a drug and read the reviews that everyone is going to react differently to the drug."

\section{Discussion}

The internet is a major source of information and community, especially among young adults, who report the highest levels of online presence; 93\% of young adults between the ages 18 and 29 go online (Lenhart, Purcell, Smith \& Zikhur, 2010). This paper is the first to capture the voices of YAMHC as they explain how they use the internet to access information and support about their mental health.

Findings indicate that YAMHC look up information related to their mental health, especially information about their medications and diagnoses, and use that information to help them with their care. Previous research has indicated that most young adults look up health information online, with 33\% accessing information about mental health issues (Fox \& Jones, 2009). This study adds insight to previous literature by revealing some of the motivations that young adults 
have for looking up information online. More specifically, young adults report that they use online information to challenge what they hear from a health care provider, or to help them prepare for a visit. Online information is also used to explore treatment options, better understand one's mental health condition, and be better educated about the side effects of prescribed medications. They also use the internet to access mental health information because of its anonymous environment or because they believe they do not have another source of free, accessible information.

Yet, the internet is not always an ideal source of information as the YAMHC in this study report feeling overwhelmed by the amount of information available online as well as wary of the accuracy of the information. Such caution is warranted as previous studies have documented the low levels of quality information found on mental health websites (see Reavely \& Jorm, 2011 for a review). This study suggests that it may be useful to teach young adults how to search effectively for health information online, and also how to evaluate the quality of that information once found.

Finally, participants from this study report finding community as they look up mental health information on more interactive sites such as message boards and blogs. This finding has been reported in previous research (Gowen, Deschaine, Gruttadaro, \& Markey, 2012), and have both positive and negative implications. On the positive side, young adults may feel less isolated and less stigmatized by learning via online communities about others who have similar mental health challenges. On the negative side, the information provided by these online communities may provide less medically accurate information about mental health conditions. Further research is needed to better understand how online communities can help and/or hinder young adults in their management of their mental health. 
This study should be considered exploratory and therefore results should be interpreted with caution. Data were collected from three focus groups, all within one state. Participants were all current internet users and predominately white, and therefore may not represent the general population of YAMHC. Using a variety of recruitment methods (e.g., online recruitment and reaching out to established communities), while possibly a strength of this study, also could have created unintentional sampling biases.

Despite these limitations, this study is the first to examine how young people with mental health conditions use the internet to access information about their mental health and treatments. The results of this study suggest that YAMHC use the internet to access information about their mental health, and that the motivations for seeking this information include supplementing or replacing other forms of mental health care, as well as building community and accessing information in a safe, anonymous environment. Mental health providers should ask about their young adult clients' internet use as it relates to mental health information seeking and ask those clients how they use that information, as well as how they know the information they read is trustworthy. It may be beneficial for mental health providers to provide a list of websites that contain scientifically-accurate information. However, it may be challenging to find sites that are both scientifically accurate and also appealing to young adults (e.g., sites that use youth-friendly language, are visually appealing, and highly interactive).

More research needs to be done to ascertain more precisely how young adults living with mental illness use the internet to access information and support. This work should be replicated using populations from different geographical areas; that are more ethnically diverse, and; come from different residential settings. While some instances of convergence were found among these three focus groups, a larger sample would also strengthen future research. Questions about the 
actual online search process and how a YAMHC decides whether a website is trustworthy or not are also worth considering. More research is also needed to ascertain how online mental health information is utilized by YAMHC, if such usage improves mental health conditions, and, if so, in what ways. Examining how online information and communities might impact the helpseeking behaviors of YAMHC, or the healthcare experience itself are also research questions that should be explored if we are to better serve this population. 


\section{References}

Arnett, J. J. (2000). Emerging Adulthood: A theory of development from the late teens through the twenties. American Psychologist, 469-480.

Bethell C.D., Read D., Stein R.E.K., Blumberg S.J., Wells N., and Newacheck P.W. (2002). Identifying children with special health care needs: development and evaluation of a short screening instrument. Ambulatory Pediatrics, 2, 38-47.

Biddle, L., Donovan, J., Sharp, D., \& Gunnell, D. (2007). Explaining non-help-seeking amongst young adults with mental distress: A dynamic interpretive model of illness behaviour. Sociology of Health \& Illness, 29, 983-1002.

Boyatzis, R. E. (1998). Transforming Qualitative Information: Thematic Analysis and Coding Development. Thousand Oaks, CA: Sage Publications.

Callahan, S.T., \& Cooper, W.O. (2005). Uninsurance and health care access among young adults in the United States. Pediatrics, 116, 88 -95.

Callahan, S.T., \& Cooper, W.O. (2006). Access to health care for young adults with disabling chronic conditions. Archives of Pediatrics and Adolescent Medicine, 160, 178 -182.

Davis, M. \& Koroloff, N. (2006). The great divide: How public health mental health policy failes young adults. In W. H. Fisher (Ed.), Community based mental health services for children and adolescents (Vol. 14, pp. 53-74). Oxford, UK: Elsevier Sciences.

Davis, M., \& Sondheimer, D. L. (2005). State child mental health efforts to support youth in transition to adulthood. Journal of Behavioral Health Services \& Research, 32, 27-42. 
Fishman, E. (2001). Aging out of coverage: young adults with special health needs. Health Affairs, 20, $254-266$.

Fox, S., \& Jones, S. (2009). The Social Life of Health Information. Washington, DC: Pew Internet and American Life.

Fox, S., \& Rainie, L. (2002). Vital Decisions: How Internet users decide what information to trust when they or their loved ones are sick. Washington, DC: Pew Internet and American Life.

Gowen, L. K., Deschaine, M., Gruttadaro, D., \& Markey, D. C. (2012). Young adults with mental health conditions and social networking websites: Decreasing social isolation. Psychiatric Rehabilitation Journal, 35, 245-250.

Griffiths, K. M., \& Christensen, H. (2000). Quality of web based information on treatment of depression: cross sectional survey. British Medical Journal, 321, 1511-1515.

Kamberelis, G. \& Dimitriadis, G. (2005). Focus groups: Strategic articulations of pedagogy, politics, and inquiry. In N. K. Denzin and Y. S. Lincoln (Eds.) The Sage Handbook of Qualitative Research (3rd edition). Thousand Oaks, CA: Sage Publications, 887-908.

Kessler, R.C., Barker, P.R., Colpe, L.J., Epstein, J.F., Gfroerer, J.C., Hiripi, E., Howes, M.J, Normand, S-L.T., Manderscheid, R.W., Walters, E.E., and Zaslavsky, A.M. (2003). Screening for serious mental illness in the general population. Archives of General Psychiatry. 60(2), 184-189. 
Khazaal, Y., Chatton, A., Cochand, S., Hoch, A., Khankarti, M. B., Khan, R., \& Zullino, D. F. (2008). Internet use by patients with psychiatric disorders in search for general and medical informations. Psychiatric Quarterly, 79, 301-309.

Khazaal, Y., Chatton, A., Cochland, S., \& Zullino, D. (2008). Quality of web-based information on cocaine addiction. Patient Education and Counseling, 72, 336-341.

Khazaal, Y., Fernandez, S., Cochand, S., Reboh, I., \& Zullino, D. (2008). Quality of web-based information on social phobia: A cross-sectional study. Depression and Anxiety, 25, 461-465.

Kruger, R. A., \& Casey, M. A. (2008). Focus groups: A practical guide for applied research $\left(4^{\text {th }}\right.$ ed.). Thousand Oaks, CA: Sage Publications.

Lenhart, A., Purcell, K., Smith, A., \& Zikhur, K. (2010). Social Media and Mobile Internet Use Among Teens and Young Adults. Washington, DC: Pew Internet and American Life Project.

Marshall, C. \& Rossman, G.B. (2011). Designing Qualitative Research (5th ed.). Los Angeles: Sage.

McManus M.A., Newacheck, P.W., \& Greaney, A.M. (1990). Young adults with special health care needs: prevalence, severity, and access to health services. Pediatrics, 86, 674 - 682.

Pottick, Bilder, Stoep, Warnder, \& Alvarez, 2008

Powell, J., \& Clarke, A. (2006). Internet information-seeking in mental health: Population survey. British Journal of Psychiatry, 189, 273-277.

Reavely, N. J., \& Jorn, A. F. (2011). The quality of mental disorder websites: A review. Patient Education and Counseling, 85, e16-e25. 
Schulenberg, J. E., Sameroff, A. J., \& Cicchetti, D. (2004). The transition to adulthood as a critical juncture in the course of psychopathology and mental health. Development and Psychopathology, 16, 799-806.

Skinner, H., Biscope, S., Poland, B., \& Goldberg, E. (2003). How adolescents use technology for health information seeking: Implications for health professionals from focus groups. Journal of Medical Information Research. Doi: 10.2196/jmir.5.4.e32.

Skinner, H. A., Maley, O., \& Norman, C. D. (2006). Developing internet-based eHealth promotion programs: The spiral technology action research (STAR) model. Health Promotion Practice, 7, 406-417.

Vogel, D. L., Wade, N. G., \& Haake, S. (2006). Measuring the self-stigma associated with seeking psychological help. Journal of Counseling Psychology, 53(3), 325-337. 
Table of Mental Health Topics Searched for Online

\begin{tabular}{|c|c|c|c|}
\hline $\begin{array}{l}\text { Mental Health } \\
\text { Topics }\end{array}$ & $\begin{array}{l}\text { \# of } \\
\text { Groups }\end{array}$ & Definition & Examples \\
\hline Medications & $3 / 3$ & $\begin{array}{l}\text { Looking up online } \\
\text { information related to } \\
\text { medication, such as side } \\
\text { effects, reason for medication, } \\
\text { interaction concerns. }\end{array}$ & $\begin{array}{l}\text { "When the doctor prescribes me } \\
\text { meds, I will look them up” } \\
\text { “Information on the drugs you } \\
\text { can take and the side effects” }\end{array}$ \\
\hline Diagnoses & $3 / 3$ & $\begin{array}{l}\text { Looking up online } \\
\text { information related to } \\
\text { diagnoses such as prevalence } \\
\text { or symptoms of condition. } \\
\text { Also the act of self- } \\
\text { diagnosing using the internet. }\end{array}$ & $\begin{array}{l}\text { "You can look up schizophrenia } \\
\text { to see what the symptoms are.” } \\
\text { "'Research different types of } \\
\text { bipolar disorder.” }\end{array}$ \\
\hline $\begin{array}{l}\text { Treatment } \\
\text { Options }\end{array}$ & $2 / 3$ & $\begin{array}{l}\text { Looking up online } \\
\text { information related to } \\
\text { different medication options, } \\
\text { alternative/holistic treatments. }\end{array}$ & $\begin{array}{l}\text { “I like to look up therapy } \\
\text { methods” } \\
\text { “Knowing about my treatment } \\
\text { options.” }\end{array}$ \\
\hline $\begin{array}{l}\text { Access to } \\
\text { Health Care }\end{array}$ & $2 / 3$ & $\begin{array}{l}\text { Looking up online } \\
\text { information related to } \\
\text { insurance coverage, local } \\
\text { clinics, sliding scale payment } \\
\text { options, transportation to care } \\
\text { facility. }\end{array}$ & $\begin{array}{l}\text { "Who is in your insurance } \\
\text { preferred network.” } \\
\text { "'I look up the county mental } \\
\text { health clinic.” }\end{array}$ \\
\hline $\begin{array}{l}\text { Supports and } \\
\text { Resources }\end{array}$ & $3 / 3$ & $\begin{array}{l}\text { Looking up online } \\
\text { information related to local } \\
\text { community resources (food } \\
\text { stamps); coping skills. }\end{array}$ & $\begin{array}{l}\text { "Things to keep you happy and } \\
\text { coping tools.” } \\
\text { “Food stamps and social } \\
\text { security.” }\end{array}$ \\
\hline
\end{tabular}


Table of Motivations for Going Online to Acquire Mental Health Information:

\begin{tabular}{|c|c|c|c|}
\hline Motivation & $\begin{array}{l}\# \text { of } \\
\text { Groups }\end{array}$ & Definition & Examples \\
\hline $\begin{array}{l}\text { Additional } \\
\text { information }\end{array}$ & $3 / 3$ & $\begin{array}{l}\text { Looking up online } \\
\text { information in order to } \\
\text { follow up from health visit; } \\
\text { obtain more information on } \\
\text { prescribed medications. }\end{array}$ & $\begin{array}{l}\text { "What does this diagnosis do } \\
\text { to a normal life?” } \\
\text { "I am going to check out what } \\
\text { that medication label means } \\
\text { and get back to you [doctor] } \\
\text { next week." }\end{array}$ \\
\hline Community & $3 / 3$ & $\begin{array}{l}\text { Using the internet in order to } \\
\text { feel less isolated; meet } \\
\text { people with similar } \\
\text { experiences/diagnoses. }\end{array}$ & $\begin{array}{l}\text { "You see there are other } \\
\text { people out there with what you } \\
\text { have" } \\
\text { "Community is really } \\
\text { important." }\end{array}$ \\
\hline $\begin{array}{l}\text { Nowhere else } \\
\text { to turn }\end{array}$ & $2 / 3$ & $\begin{array}{l}\text { Looking up online } \\
\text { information because of lack } \\
\text { of health insurance; wanting } \\
\text { information when services } \\
\text { are closed. }\end{array}$ & $\begin{array}{l}\text { "When you're not insured you } \\
\text { need the internet" } \\
\text { "If it's two in the morning, the } \\
\text { information is right there." }\end{array}$ \\
\hline $\begin{array}{l}\text { Prepare for a } \\
\text { health visit }\end{array}$ & $2 / 3$ & $\begin{array}{l}\text { Looking up online } \\
\text { information on mental health } \\
\text { before a health visit; look up } \\
\text { health care provider ratings. }\end{array}$ & \\
\hline Anonymity & $2 / 3$ & $\begin{array}{l}\text { Looking up online } \\
\text { information in order to not } \\
\text { have to disclose identity. }\end{array}$ & $\begin{array}{l}\text { "It's totally private” } \\
\text { "It's a mixture of anonymity } \\
\text { and credibility.” }\end{array}$ \\
\hline
\end{tabular}

